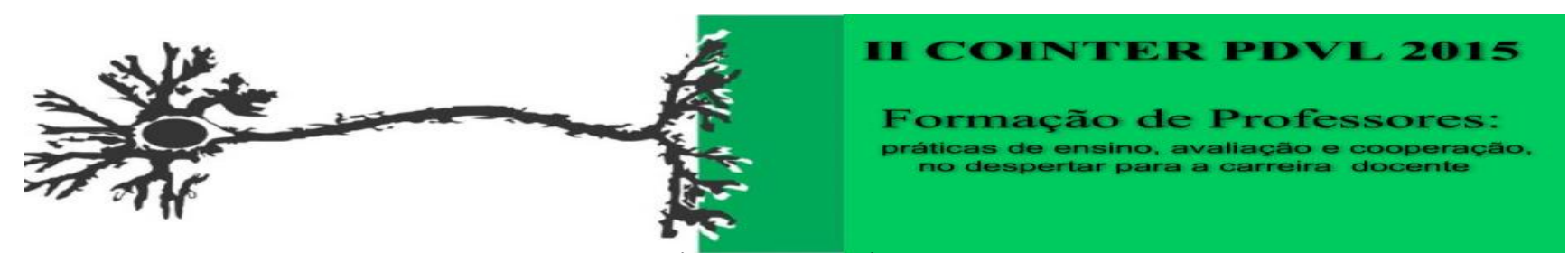

\title{
CRAQUEAMENTO TERMOCATALÍTICO DE ÓLEO DE BABAÇU SOBRE MATERIAIS NANOESTRUTURADOS DO TIPO AISBA-15
}

\author{
Apresentação: Comunicação Oral \\ Autor Principal $^{1}$ : Eduardo Henrique Borges Castelo Branco \\ Orientador $^{2}$ : Ms. Cícero Oliveira Costa Neto
}

\section{Resumo}

Visto o crescente interesse da ciência em obter biocombustíveis, com frações semelhantes à gasolina e ao diesel, através de processos menos poluentes que os de transesterificação, a obtenção de biocombustíveis renováveis a partir do craqueamento termocatalítico do óleo de babaçu (Orbignya phalerata) sobre materiais nanoestruturados do tipo AlSBA-15 tem se mostrado uma excelente opção. Por apresentar uma estabilidade térmica e hidrotémica, o $\mathrm{Al}_{75} \mathrm{SBA}-15$ foi o que mostrou maior eficácia no processo de craqueamento do óleo vegetal. Todos os processos de síntese e craqueamento foram realizados no prédio de Núcleo Interinstitucional de Estudo e Geração de Novas Tecnologias - GERATEC, localizado na Universidade Estadual do Piauí, em Teresina.

Palavras-Chave: Craqueamento, AlSBA-15, Biodiesel, Óleo de Babaçu, catalisador.

\footnotetext{
${ }^{1}$ Licenciatura Plena em Química, Universidade Estadual do Piauí, edu14_henrique@hotmail.com

${ }^{2}$ Química Analítica, Universidade Estadual do Piauí, cícero.uespi@gmail.com
} 


\section{Introdução}

Nas últimas décadas, a humanidade vem ampliando métodos de obtenção de energia, tanto para suprir suas necessidades básicas como para minimizar os problemas ambientais, sendo que o crescente consumo de energia, por quase toda população mundial, tem causado preocupações, pois houve um aumento significativo da temperatura, do derretimento de gelo das calotas polares e o aumento no nível de água dos oceanos, além de inundações e secas que acarretam sérios prejuízos à população. O agravamento destes fenômenos pode ter ocorrido, devido ao aumento das concentrações de gases que provocam o efeito estufa, resultante das emissões realizadas pela atividade humana. Além disso, a necessidade de ampliação das fontes renováveis de energia tem chamado atenção da comunidade cientifica e dos órgãos fomentadores de pesquisas para obtenção de combustíveis renováveis.

A busca de fontes alternativas na produção de combustíveis renováveis vem ganhando grande destaque no cenário brasileiro, vários estudos tem se intensificado na produção de biodiesel, no qual apontam "o biodiesel" como alternativa interessante em comparação aos combustíveis fósseis, por possibilitar a redução das emissões de gases nocivos ao ambiente e a saúde humana.

A produção do biodiesel se dar por diferentes rotas, sendo que a mais vantajosa é o processo de produção por craqueamento, em comparação com os processos de transesterificação e esterificação. O craqueamento de óleos vegetais proporciona frações líquidas de biocombustível semelhante ao combustível de origem mineral e pode ser meramente térmico ou termocatalítico, e consiste no rompimento das ligações de moléculas de óleo vegetal de cadeia carbônica maiores e mais complexas em moléculas mais simples e leves.

Os óleos vegetais têm grande potencial para produção de biodiesel, pois são compostos basicamente de triglicerídeos, formado pela reação de um tri-álcool (glicerol) com três moléculas de ácidos graxos. Os ácidos graxos presentes na cadeia carbônica dos óleos variam de 8 a 12 átomos de carbono com diferentes graus de insaturações dependendo da oleaginosa. Existe, portanto a oportunidade de utilizar várias sementes oleaginosas para a obtenção de biodiesel devido à variedade de semente encontrada nas diversas regiões do país. Dentre os diversos óleos vegetais, vale destacar o óleo de babaçu (Orbignyaphalerata), no qual apresenta composição basicamente saturada, sendo uma característica excelente para a produção do biodiesel, cujas cadeias carbônicas variam de 8 a 18 átomos de carbono.

Vários catalisadores estão sendo desenvolvido com o objetivo de melhorar a obtenção de diesel, utilizando o craqueamento termocatalítico de óleos vegetais. Estudos mostram que sólidos com estruturas ordenadas de poros e com sítios ácidos são mais seletivos para as citadas frações 
líquidas, além disso, pode-se destacar também um aumento da seletividade da fração semelhante ao diesel à medida que há um aumento do diâmetro de poros do catalisador sólido.

Neste contexto, os materiais nanoestruturados em especial, a peneira molecular do tipo SBA-15, apresenta-se como um material promissor, pois possuem elevado diâmetro médio de poros e elevadas estabilidades térmica e hidrotérmica. Além do mais, podem adquirir sítios ácidos quando um metal é impregnado no seu processo de formação, modificando favoravelmente as propriedades catalíticas do material, promovendo assim a formação de sítios ácidos (ARAUJO e JARONIEC, 1999; SHAO et. al., 2005).

\section{Fundamentação Teórica}

\section{Biodiesel}

O biodiesel surgiu em meados do século XX como uma proposta de combustível em substituição do combustível fóssil "petróleo". A queima de combustível de origem fóssil emite gases poluentes na atmosfera como, por exemplo, enxofre e carbono, que danifica a camada de ozônio e degradam o meio ambiente, prejudicando a vida no planeta (SANTOS e PINTO, 2009). Alem de ser de difícil obtenção e processamento com elevado custo para sua extração e transformação em energia.

Diferente do petróleo o biodiesel é renovável, biodegradável, não tóxico e, é considerado "limpo", podendo ser obtido a partir de plantas oleaginosas, gorduras animais e residuais. Sua produção pode ser realizada pelo craqueamento, também conhecido como pirodiesel, que consiste na quebra das moléculas do óleo (triglicerídeos) formando hidrocarbonetos a altas temperaturas (DOMINGOS et al., 2012).

O biodiesel foi misturado à gasolina com a finalidade de substituir a tetraetila de chumbo que era utilizada como aditivos da gasolina na otimização da reação de combustão, porém causava sérios prejuízos ao meio ambiente e a saúde da população. Apesar disso, a tetraetila de chumbo contribuiu satisfatoriamente para o desenvolvimento tecnológico dos motores em geral (DOMINGOS et al., 2012).

No Brasil a mistura do biodiesel à gasolina passou a ser introduzida a partir da Lei $n^{\circ} 11097 / 05$ de 13 de janeiro de 2005, no qual regulamenta em 2008 a condição de mistura do diesel como aditivo da gasolina sendo obrigatório o uso intermediário de $2 \%$ do biodiesel no diesel e a partir de 2013 o valor fixo de 5\% de adição ao óleo diesel pelo consumidor final (SANTOS e PINTO, 2009). 
Os benefícios desta energia alternativa são muitos, pois além de ser uma tecnologia limpa e não poluente, traz vantagens econômicas, sociais e apresenta melhores características físicoquímicas do que os combustíveis convencionais.

\section{Craqueamento Termocatalítico}

O craqueamento termocatalítico de óleos e gorduras é realizado na presença de catalisadores, no qual não altera significativamente a composição dos produtos, mas favorece a determinadas rotas, ou seja, a distribuição dos mesmos, já que certas etapas do processo são facilitadas ou dificultadas (IDEM et al., 1997; QUIRINO, 2006; BENSON et al., 2009).

Segundo Barbosa 2012, O uso de catalisadores em processo, de obtenção de biocombustíveis a partir de óleos e gorduras, pode resultar na otimização do tempo de reação química e também induzir os reagentes para formação de maiores alíquotas dos produtos mais desejados, pela formação de novos intermediários e pela seletividade química inerente a cada tipo de catalisador. O grau de acidez, a porosidade do material e outros fatores físico-químicos ligados aos materiais usados como catalisador ou precursores catalíticos contribuem para a seletividade verificada após análises químicas dos produtos de craqueamento.

Os catalisadores agem somente no craqueamento secundário e nas reações de desidrogenação e aromatização (IDEM et al., 1997). Catalisadores com estruturas de poros bem definidas, com sítios ácidos e elevada estabilidade térmica e hidrotérmica são mais seletivos para as citadas frações liquidas semelhantes à gasolina e ao diesel mineral (OOI et al., 2007).

Pesquisas mostram que sólidos com elevados números de sítios ácidos de Bronsted, no interior dos poros, são capazes de impulsionar a desoxigenação dos ácidos graxos dos óleos vegetais e tendem a favorecer a formação, preferencialmente de hidrocarbonetos aromáticos, alifáticos e cíclicos e lineares, com tamanho de cadeia próxima a faixa da gasolina (SUAREZ et al., 2007;TWAIQ et al., 2003;OOI et al., 2007).

Estudos apontam que determinados metais, como terras raras ou alumínio, podem ser incorporados aos catalisadores com estrutura definida, afim de, proporcionar um aumento da estabilidade térmica e hidrotérmica, além de favorecer as propriedades catalíticas do material promovendo a formação de sítios ácidos (ARAUJO e JARONIEC, 1999; SHAO et al., 2005). Porém a incorporação excessiva do metal provoca a distorção da estrutura cristalina do catalisador, diminuído a intensidade do craqueamento secundário (OOI et al., 2007).

Vários catalisadores já foram estudados, dentre eles zeólitas (IDEM et al., 1997) materiais mesoporosos (TWAIQ et al., 2004; OOI et al., 2004), sílicas e aluminas, amorfos (QUIRINO, 2006; RIBEIRO, 2006). 
Estudos relatam que, o craqueamento secundário de um material amorfo e bem intensificado, devido à dificuldade de difusão das moléculas de hidrocarbonetos pelos poros e pela fixação dessas moléculas na superfície dos sítios ácidos (RIBEIRO, 2006; QUIRINO, 2006). Já em sólidos cristalinos o processo é inibido, devido à facilidade com que as moléculas atravessam os poros do catalisador (IDEM et al., 1997).

Os materiais mesoporosos vêm sendo estudados como catalisadores, pois possuem boas características, como estrutura de poros e volume bem ordenados, alta área superficial e maior estabilidade térmica e hidrotérmica que os outros materiais. Vários materiais mesoporosos tem sido alvo de pesquisas, dentre eles, a SBA 15, que apresenta as citadas características e são comumente empregadas em reações de craqueamento.

\section{SBA-15}

A SBA-15 é uma família de material mesoporoso, descoberto por pesquisadores da Universidade de Santa Bárbara, na Califórnia, no final da década de 90. Apresenta estrutura hexagonal bem definida, como mostra a figura 1, canais de dimensão $2 \mathrm{D}$, volumes de poros grandes

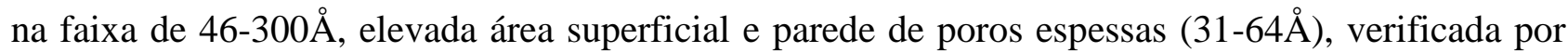
sua estabilidade térmica e hidrotérmica, comparada aos materiais da família M41S (ZHÃO et al., 1998).

As micelas do surfactante é a responsável pela determinação da estrutura dos materiais mesoporosos, sendo importante como modelo para a montagem e subseqüente condensação de precursores inorgânicos. Podem ser três tipos: catiônico, aniônico e não aniônico, sendo o seu tamanho, carga e forma, indispensáveis na formação da estrutura (GAO et al., 2006).

\section{Óleo de babaçu}

O babaçu (Orbignyaphalerata) é uma palmeira de grande porte (até 20m), como mostra a Figura 5, de tronco cilíndrico e copa em formato de copa. O óleo de babaçu é formado predominantemente da condensação entre glicerol e ácidos graxos formando ésteres, os quais são denominados triacilglicerídeos, e cujas cadeias carbônicas variam de 8 a 18 átomos de carbonos. Quando desoxigenados, os ácidos graxos presentes podem possibilitar a obtenção de hidrocarbonetos na faixa do diesel mineral (C9 e C22) (LIMA, 2007).

Os frutos se apresentam em formato elipsoidal, mais ou menos cilíndrico e são constituídos de epicarpo (camada mais externa e bastante rijo), mesocarpo (rico em amido), endocarpo (rijo) e amêndoas (de 3 a 4 por fruto), sendo ilustrado na Figura 6, o tamanho e a composição média de fruto do babaçu. O côco tem aproximadamente 8 a $15 \mathrm{~cm}$ de comprimento. O óleo de babaçu é 
constituído por $85 \%$ de ésteres de ácidos graxos saturados, característica excelente para a produção de biodiesel.

\section{Metodologia}

\section{Craqueamento térmico}

O craqueamento térmico do óleo de babaçu será realizado em destilação simples, constituído de um balão de $250 \mathrm{~mL}$, condensador, uma manta aquecedora e um termopar e termômetro, utilizado para medir a temperatura no fundo do balão. Os ensaios serão realizados em triplicata com 100 g do óleo de babaçu. Em cada um dos ensaios, a massa do óleo será transferida para o balão de destilação onde será aquecido da temperatura ambiente até $400{ }^{\circ} \mathrm{C}$, a uma taxa de aquecimento de $10{ }^{\circ} \mathrm{C} / \mathrm{min}$. A reação será acompanhada por meio da coleta de alíquotas e medida do índice de acidez.

\section{Craqueamento termocatalítico}

O craqueamento termocatalítico do de óleo babaçu sobre a amostra AlSBA-15 será realizado de forma semelhante ao processo térmico descrito anteriormente. No entanto, em conjunto com o óleo, será adicionada ao balão de destilação $2 \%$ em massa de catalisador (AlSBA-15) previamente ativada a $400{ }^{\circ} \mathrm{C}$, em estufa, e resfriada a temperatura ambiente em um dessecador.

\section{Caracterização das Amostras de Diesel Verde (DV) Obtidas nos Craqueamentos Térmico e Termocatalíticos do Óleo de Babaçu}

A acidez das duas frações líquidas orgânicas coletadas será determinada por titulação ácidobase, usando como titulante uma solução metanólica de hidróxido de potássio a 0,1 mol/L, conforme o método AOCS Cd3d363, citado e descrito por Ribeiro (2006) e Quirino (2006). Cada amostra será analisada em triplicata, tomando-se alíquotas de $1 \mathrm{~g}$ diluídas em $10 \mathrm{~g}$ de solvente composto de uma mistura 1:1 de tolueno e isopropanol, segundo o método da AOCS, e com o auxílio de fenolftaleína a $1 \%$ em isoprapanol. As análises de infravermelho serão realizadas gotejando as amostras de líquido orgânico sobre uma pastilha ou janela de $\mathrm{KBr}$, a qual, posteriormente, será submetida à análise espectroscópica no infravermelho médio. As medidas da intensidade das bandas de absorbância relativas ao estiramento $\mathrm{C}=\mathrm{O}$ de ácido carboxílico serão utilizadas para avaliar a ação desoxigenante dos catalisadores no craqueamento termocatalítico do óleo de babaçu. As duas frações líquidas orgânicas coletadas terão suas propriedades físicoquímicas determinadas de acordo com as principais normas estabelecidas pela Agência Nacional de 
Petróleo (ANP) para a gasolina (primeira fração) e o diesel mineral (segunda fração). A composição dos hidrocarbonetos será determinada por análise de destilação simulada, de acordo com a norma ASTM D 2887 estendida, realizada em um cromatógrafo gasoso Varian 450-GC equipado com um injetor automático Varian CP-8400, detector de ionização de chama (FID) e uma coluna de

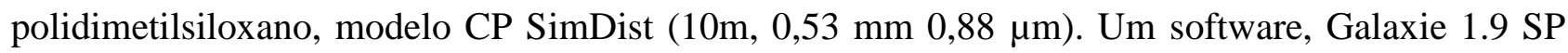
2b, será utilizado na captura e tratamento dos dados, além de fornecer as curvas de destilação simulada das amostras, fornecerá, baseado nos padrões de referência (ASTM D 2887 Reference Gas Oil, Lot. 2) e calibração (SimDist Calibration sample, C5 a C60), os cromatogramas das mesmas com os picos dos hidrocarbonetos identificados por número de átomos de carbono.

\section{Resultados e Discussão}

\section{Difração de Raios-X}

O difratograma foi utilizado para verificar a formação da estrutura mesoporosa hexagonal dos catalisadores. A figura 01 mostra os difratogramas de raios-X referente ás amostras sólidas de SBA-15 e $\mathrm{Al}_{25}$ SBA-15, $\mathrm{Al}_{50} \mathrm{SBA}-15$ e $\mathrm{Al}_{75} \mathrm{SBA}-15$ no ângulo de $2 \theta$.

Figura 01- Difratogramas de raios- $X$ dos catalisadores SBA-15 e $\mathrm{Al}_{25} \mathrm{SBA}-15, \mathrm{Al}_{50} \mathrm{SBA}-15$.

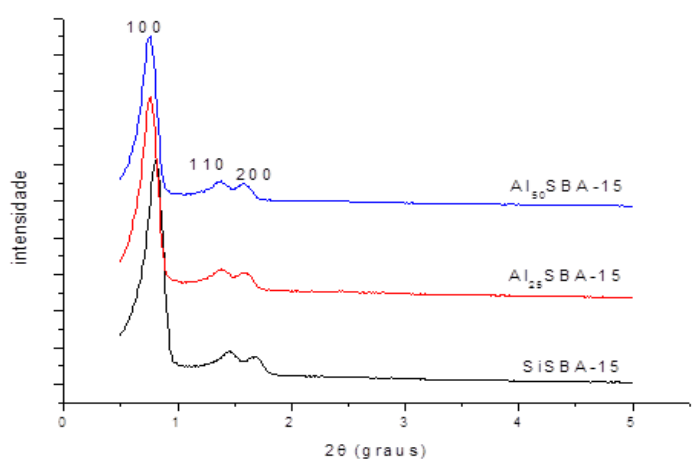

Fonte: Dados da pesquisa, 2015.

Através dos difratogramas das amostras (SBA-15 e $\left.\mathrm{Al}_{25} \mathrm{SBA}-15, \mathrm{Al}_{50} \mathrm{SBA}-15\right)$, pode-se observar que os catalisadores apresentam três picos de difração característicos de estrutura mesoporosa hexagonal com simetria P6mm referente aos planos (100), (110) e (200), entre 0,5 e $5,0^{\circ}$, que estar em conformidade com o descrito na literatura (ZHAO et al., 1998). A partir dos planos característicos, pode-se afirmar que a incorporação de alumínio e do gel de síntese não danificou as características estruturais da SBA-15. Nota-se também uma diminuição do valor do ângulo $2 \theta$ e um aumento da intensidade do pico referente ao plano (100) das amostras de $\mathrm{Al}_{25} \mathrm{SBA}$ $15, \mathrm{Al}_{50} \mathrm{SBA}-15$ com a incorporação de alumínio, indicando assim um aumento no parâmetro de 
rede, este aumento pode estar relacionado com aumento do diâmetro médio de poros ou da espessura da parede (MU et al., 2008 e LIN et al., 2011).

\section{Microscopia eletrônica de varredura (MEV)}

A microscopia de varredura permite verificar a morfologia do material e assim caracterizar a amostra. As imagens obtidas pelo MEV dos catalisadores SBA-15 e $\mathrm{Al}_{25} \mathrm{SBA}-15, \mathrm{Al}_{50} \mathrm{SBA}-15$ e $\mathrm{Al}_{75} \mathrm{SBA}-15$ estão ilustradas na figura 02.

Figura 02 -Microscopia eletrônica de varredura da amostra de SBA-15 e $\mathrm{Al}_{25} \mathrm{SBA}-15, \mathrm{Al}_{50} \mathrm{SBA}-15$ e $\mathrm{Al}_{75} \mathrm{SBA}-15$.

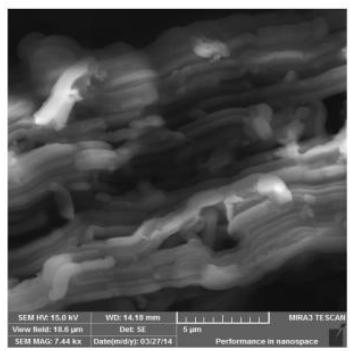

SISBA-15

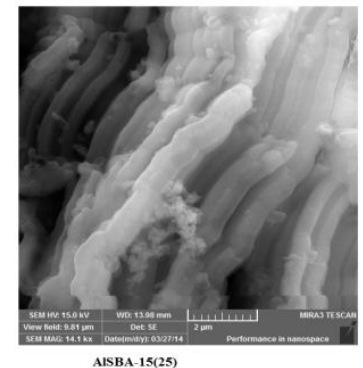

ASBA-15(25)

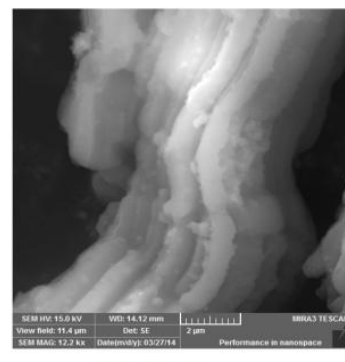

AISBA-15 (50)

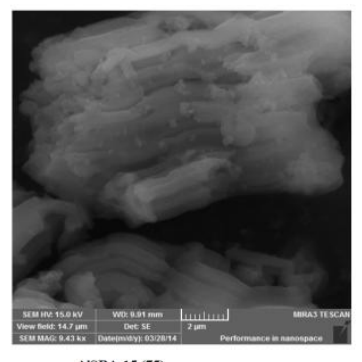

AISBA-15 (75)

Fonte: Dados da pesquisa, 2015.

Analisando a microscopia eletrônica de varredura dos catalisadores SBA-15 e $\mathrm{Al}_{25} \mathrm{SBA}-15$, $\mathrm{Al}_{50} \mathrm{SBA}-15$ e $\mathrm{Al}_{75} \mathrm{SBA}-15$, observa-se que em todas, houve a formação de uma estrutura com mesoporos cilíndricos unidirecionais que possuem superfície lisa e regulares, característico do material mesoporoso SBA-15 (ZHÃO et al., 1998). Isso significa que a incorporação de alumínio na amostra de $\mathrm{Al}_{25}$ SBA-15 não alterou a estrutura do material formado.

\section{Craqueamento térmico e termocatalítico do óleo de babaçu}

A figura 03 mostra o craqueamento termocatalítico do óleo de babaçu sobre as amostras sólidas dos catalisadores SBA-15 e $\mathrm{Al}_{25} \mathrm{SBA}-15$ que proporcionaram a obtenção de duas frações líquidas, contendo uma fase aquosa e outra orgânica.

Figura 03 - Foto das duas frações líquidas coletadas no craqueamento termocatalítico do óleo de babaçu sobre a amostra $\mathrm{Al}_{25} \mathrm{SBA}-15$. Primeira fração à esquerda; segunda fração à direita. 


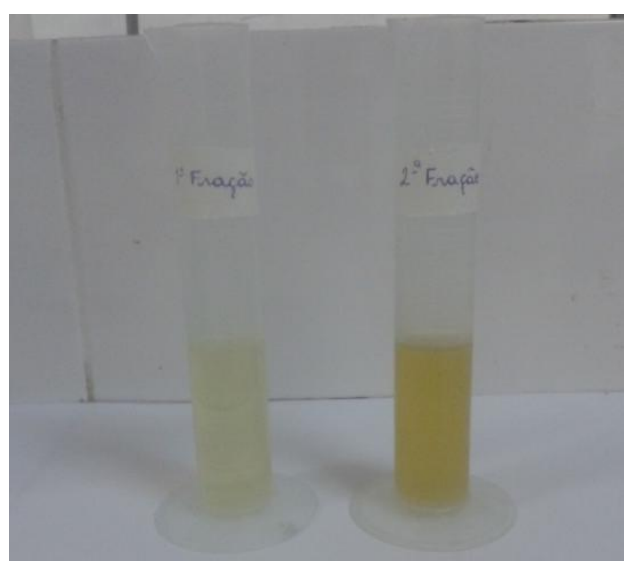

Fonte: Dados da pesquisa, 2015.

Como observado na Figura 03, às duas frações líquidas apresentam coloração esverdeada, sendo que a segunda apresentou um verde bem mais intenso. Além do mais, a primeira fração apresentou-se mais leve e fluída que a segunda, muito provavelmente, em decorrência de ter sido coletada em uma temperatura menor $\left(<190^{\circ} \mathrm{C}\right)$, e em virtude de sua rápida destilação, na qual consequentemente, apresenta compostos mais leves que aqueles presentes na segunda fração.

\section{Caracterização por espectroscopia na região do infravermelho das duas frações obtidas}

Analisando os espectros, observou-se que todos apresentam bandas características de ácidos carboxílicos, referente ao estiramento $\mathrm{C}=\mathrm{O} \mathrm{em} 1712 \mathrm{~cm}^{-1}$; no intervalo de 1210 a $1320 \mathrm{~cm}^{-}$ 1, apresentam bandas referentes ao estiramento $\mathrm{C}-\mathrm{O}$; já em $1458 \mathrm{~cm}^{-1}$, a bandas é referente à deformação $\mathrm{CH}_{2}$, e no intervalo de 2840 a $3000 \mathrm{~cm}^{-1}$, as bandas se referem aos estiramentos $\mathrm{C}-\mathrm{H}$ de $\mathrm{CH}_{3}$ e $\mathrm{CH}_{2}$, acima da larga banda de estiramento $\mathrm{O}-\mathrm{H}$ (ALBUQUERQUE et al., 2003). Além disso, observa-se uma banda de baixa intensidade em $910 \mathrm{~cm}^{-1}$, referente à vibração de deformação angular também característica de ácido carboxílico.

Comparando os espectros de absorbância do craqueamento térmico e termocatalítico, da figura 05, pode-se observar uma diminuição da intensidade de absorbância referente ao estiramento $\mathrm{C}=\mathrm{O}$, em $1712 \mathrm{~cm}^{-1}$ característica de ácidos carboxílicos, nas amostras obtidas pelo craqueamento termocatalítico, fato esse que evidencia a ação desoxigenante dos catalisadores no craqueamento. Para a amostra de SBA-15 composta basicamente de sílica, a ação desoxigenante pode estar associada á estrutura ordenada de poros, que de acordo com Idem et al.(1997), Twaiq et al. (2003) e Benson et al.(2009), favorece as reações de desoxigenação, já que possibilita a difusão das moléculas, provenientes do craqueamento primário.

Observou-se também que a ação desoxigenante da amostra de $\mathrm{Al}_{75} \mathrm{SBA}-15$ foi mais intensa, fato esse evidenciado pela diminuição da intensidade das bandas características de ácidos 
carboxílicos. Este comportamento está atribuído a incorporação do metal (alumínio), que proporciona um aumento da acidez de Lewis, na qual favorece a ocorrência de reações de desoxigenação dos ácidos graxos oriundos do craqueamento primário.

\section{Conclusões}

A partir das análises realizadas dos catalisadores SBA-15 e $\mathrm{Al}_{25} \mathrm{SBA}-15, \mathrm{Al}_{50} \mathrm{SBA}-15$ e $\mathrm{Al}_{75} \mathrm{SBA}-15$, foi possível concluir que os mesmos foram sintetizados com êxito, conforme comprovado pelas caracterização realizadas; a incorporação de alumínio nas amostras de SBA15 com razão $\mathrm{Si} / \mathrm{Al}=25,50$ e 75 não alterou significativamente a estrutura ordenada de poros das peneiras, na qual mostra o resultados da Microscopia Eletrônica de Varredura; alem disso as analises de Difração de Raios-X (DRX) com planos cristalográficos de (100), (110) e (120) são característicos da estrutura hexagonal mesoporosa; e as isotermas de adssorção/dessorção de nitrogênio indicam que os materiais sintetizados apresentam mesoporos cilíndricos unidirecionais

O craqueamento térmico e termocatalítico do óleo de babaçu, proporcionou a obtenção de duas frações liquidas, contendo uma fase aquosa e outra orgânica, sendo que ambas apresentam coloração esverdeada, e a segunda apresentou um verde bem mais intenso que a primeira. Por meio das análises de infravermelho dos craqueamentos, foi possível perceber que no craqueamento termocatalítico do óleo de babaçu sobre a amostra de $\mathrm{Al}_{75} \mathrm{SBA}-15$ ocorreu uma maior desoxigenação em virtude da presença, em maior intensidade, de sitos ácidos de Lewis na peneira molecular.

\section{Referências}

ALBUQUERQUE, M.L.S.; GUEDES, I.; ALCANTRA Jr.,P.; MOREIRA, S,G.C. Infrared absorption spectra of buriti (Mauritiaflexuosa L.) oil.Vibrational Spectroscopy, v. 33, 127-131, 2003.

ARAUJO, A. S.; JARONIEC, M. Synthesis and properties of lanthanide incorporated mesoporous molecular sieves.Journal of Colloid and Interface Science. v. 218, p. 462-467, 1999.

BARBOSA, A. R. C. Obtenção de diesel verde por craqueamentotermocatalítico de óleo de babaçu sobre bauxita. 2012. 44f. Monografia (Graduação) - Licenciatura plena em química, Universidade Estadual do Piauí, 2012. 
CARRAZZA, L. R.; SILVA, M. L. da; AVILA, J. C. C. Manual tecnológico de aproveitamento integral do fruto babaçu. Brasília- DF. Instituto sociedade, População e Natureza. Brasil, 2012.

IDEM, R. O.; KATIKANENI, S. P. R.; BAKHSHI, N. Catalytic conversion of canola oil to fuels and chemicals: roles of catalyst acidity, basicity and shape selectivity on product distribution. FuelProcessing Technology, v. 51, p. 101-125, 1997.

LIN, S.; SHI, L.; RIBEIRO CARROT, M. M. L.; CARROT, P. J. M.; ROCHA, J.; LI, M. R.; ZOU, X. D. Direct synthesis without addition of acid f Al-SBA15 with controllable porosity and high hydrothermal stability. Microporous ande mesoporousmaterials, v. 142, p. 526-534, 2011.

LUZ Jr., G. E.; LIMA, S. H.; MELO, A. C. R.; ARAUJO, A. S.; FERNANDES Jr.; V. J. DirectsynthesisandcharacterizationofLaSBA-15 mesoporous molecular sieves. Journalofmaterials Science, v. 45, p. 1117-1122, 2010.

MU, Z.; LI, J. J.; HAO, Z. P.; QIAO, S. Z. Direct synthesis of lanthanide-containing SBA-15 under weak acidic conditions and its catalytic study. Microporous and Mesoporous Materials, v. 113, p. 72-80, 2008.

SHAO, Y.; WANG, L.; ZHANG, J.; ANPO, M. Synthesis of hydrothermally stable and long-range ordered Ce-MCM-48 and Fe-MCM-48 materials.JournalofPhysicalChemistry B, v. 109, p. 20835-20841, 2005.

TWAIQ, F. A.; MOHAMED, A. R.; BHATIA, S. Liquid hydrocarbon fuels from palm oil by catalytic cracking over aluminosilicatemesoporous catalysts with various $\mathrm{Si} / \mathrm{Al}$ rations. Microporous and Mesoporous Materials, v. 64, p. 95-107, 2003.

ZHAO, D.; HUO, Q.; FENG, J.; KIM, J.; HAN, Y.; STUCKY, G. D. Nonionic triblock and star diblock copolymer and oligomeric surfactant syntheses of highly ordered, hydrothermally stable, mesoporous silica structures. Journal of American Chemical Society, v. 120, p. 6024-2036, 1998. 